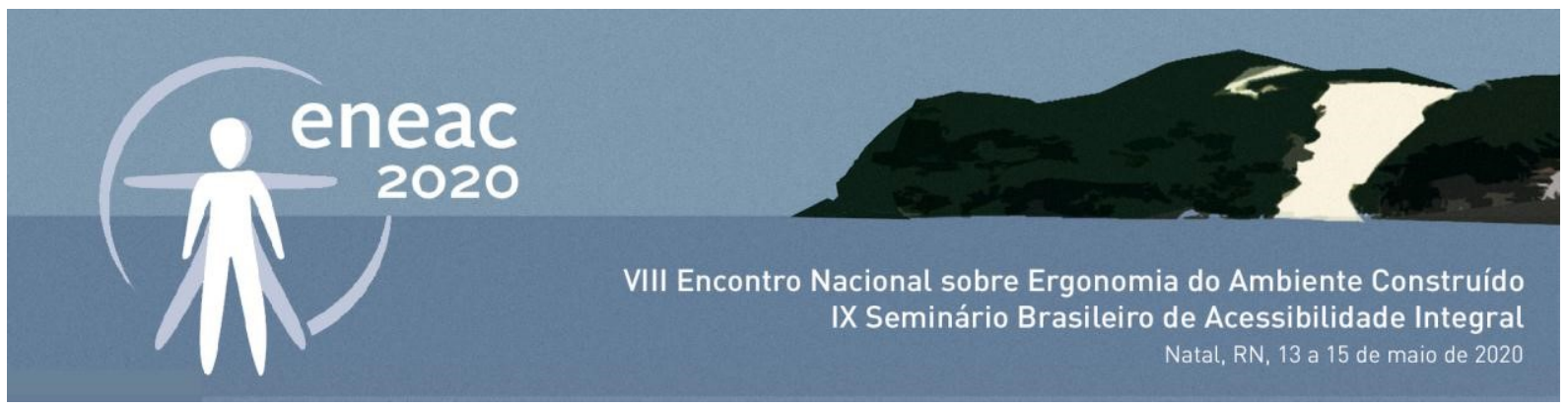

\title{
Programa Cidade Madura x NBR 9050: um estudo de caso na Unidade de João Pessoa
}

\author{
Cidade Madura Program x NBR 9050: a case study at the João Pessoa \\ Unit
}

NELMA MIRIAN CHAGAS DE ARAÚJO

Doutora,

IFPB - Campus João Pessoa, nelmamca@gmail.com

INARA BEATRIZ RODRIGUES SOARES

Técnica em Edificações, Graduanda em Design de Interiores, IFPB - Campus João Pessoa, rodriguesinara43@gmail.com

\section{RESUMO}

O processo de envelhecimento vai muito além de uma classificação cronológica. Ou seja, causa mudanças psicológicas e biológicas que variam de acordo com a realidade socioeconômica dos diferentes grupos e, portanto, requerem mudanças no ambiente construído para garantir o bemestar do idoso. Existem poucas edificações em que o público brasileiro mais velho se sinta confortável e quando restringimos a área de pesquisa ao estado da Paraíba, essa quantidade se torna ainda menor. Dentro desse contexto, o presente trabalho aborda a arquitetura residencial independente para idosos, através de um estudo de caso do Programa Cidade Madura, no que diz respeito a sua adequação às disposições contidas na NBR 9050. Como resultado da pesquisa realizada, constata-se que o condomínio não apresenta uma arquitetura completamente satisfatória, mas proporciona um espaço em que os moradores são protegidos, integrados e incentivados a permanecerem ativos e derrubar a visão preconceituosa que os classifica como incapazes.

PALAVRAS-CHAVE: acessibilidade, Programa Cidade Madura, terceira idade, ambiente construído

\section{ABSTRACT}

The aging process goes far beyond a chronological classification. That is, it causes psychological and biological changes that vary according to the socioeconomic reality of the different groups and, therefore, require changes in the built environment to guarantee the well-being of the elderly. There are few buildings in which the older Brazilian public feels comfortable and when we restrict the research area to the state of Paraíba, that amount becomes even smaller. Within this context, the present work addresses the independent residential architecture for the elderly, through a case study of the Cidade Madura Program, with regard to its adequacy to the provisions contained in NBR 9050. As a result of the research, it appears that the condominium does not present a completely 


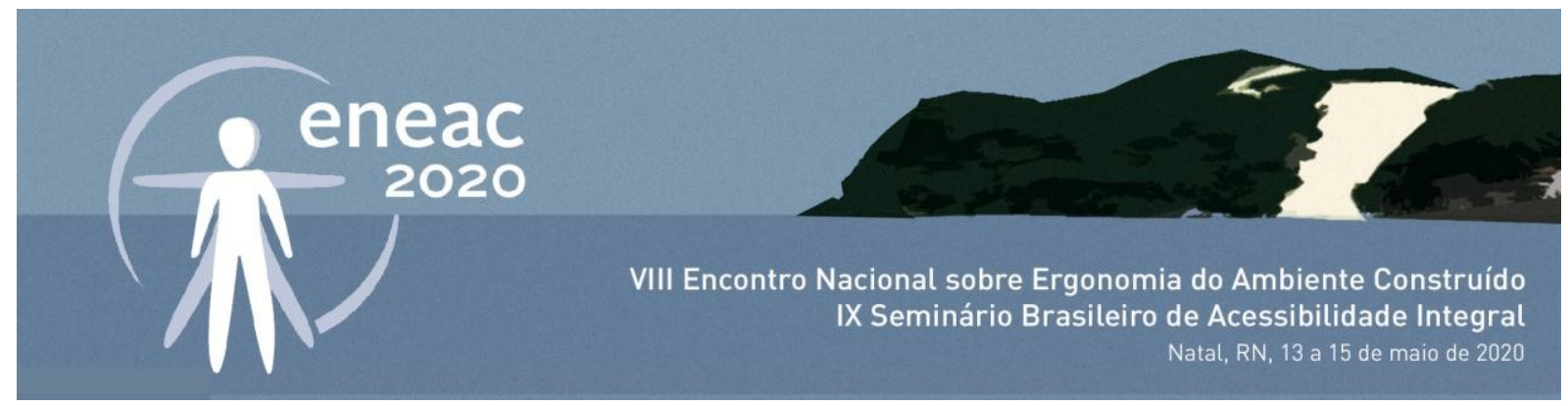

satisfactory architecture, but it does provide a space in which residents are protected, integrated and encouraged to remain active and overthrow the prejudiced view that classifies them as incapable.

KEYWORDS: accessibility, Mature City Program, old man, built environment

\section{INTRODUÇÃO}

O processo de envelhecimento vai muito além de uma classificação cronológica. Ou seja, causa mudanças psicológicas e biológicas que variam de acordo com a realidade socioeconômica dos diferentes grupos e, portanto, requerem mudanças no ambiente construído para garantir o bemestar do idoso.

O aumento da expectativa de vida da população tem sido uma realidade presente em todo o mundo, inclusive no Brasil, devido a diversos fatores, tais como: avanço tecnológico, evolução científica, mudança de hábitos etc. Brum, Tocantins e Silva (2005) apud Queiroz (2010, p. 16) afirmam que "Diversos estudiosos têm se preocupado com essa questão e estima-se que em 2025 o Brasil será o sexto país com a maior população de idosos no mundo".

De acordo com o Estatuto do Idoso (BRASIL, 2013), no seu Art. 37: "O idoso tem direito à moradia digna, no seio da família natural ou substituta, ou desacompanhado de seus familiares, quando assim o desejar, ou, ainda, em instituição pública ou privada". Ressaltando-se que o Art. 38 ainda garante, entre outras coisas, a "eliminação de barreiras arquitetônicas e urbanísticas, para garantia de acessibilidade ao idoso".

No entanto, uma parcela significativa do mercado da construção civil não tem acompanhando essa mudança de cenário e, como consequência disso, essa população tem sofrido com a falta de ambientes residenciais adaptados às suas necessidades. Existem poucas edificações em que o público brasileiro mais velho se sinta confortável e quando restringimos a área de pesquisa ao estado da Paraíba, essa quantidade se torna ainda menor.

Segundo Barros (2000) apud Vinagre (2016, p. 5), o Brasil tinha cerca de 13 milhões de pessoas com mais de 60 anos, que são responsáveis por um terço dos atendimentos de lesões traumáticas nos hospitais, segundo o SUS - Sistema Único de Saúde. Ainda segundo o autor, aproximadamente 75\% dessas lesões acontecem nas próprias casas dos pacientes, em quedas que poderiam ser evitadas em ambientes mais favoráveis, com um índice de melhoria da qualidade de vida bastante apreciável, já que $34 \%$ das quedas gera algum tipo de fratura.

Assim, se faz mister compreender e atender as necessidades espaciais dos idosos, de forma que o ambiente construído possa incorporar as recomendações técnicas e legislações pertinentes, garantindo, dessa forma, uma boa qualidade de vida para esse grupo social cada vez mais representativo da população brasileira.

A temática abordada neste artigo é a arquitetura residencial para a terceira idade independente, de forma a poder avaliar os ambientes utilizados por essa população em um condomínio residencial projetado para ela. A avaliação do ambiente construído foi efetuada à luz da NBR 9050 (ABNT, 2015). 


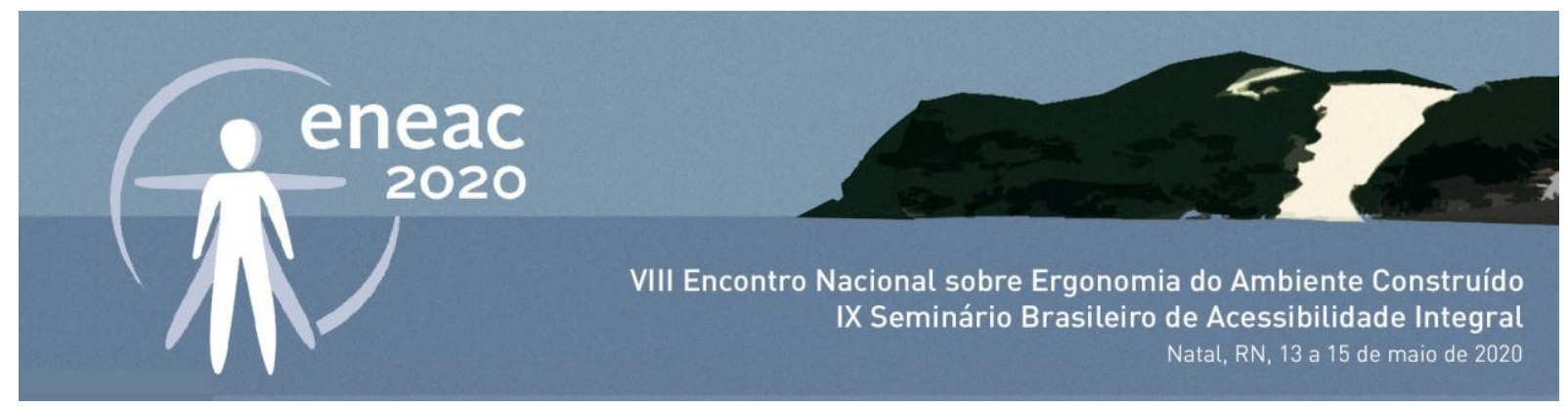

\section{TERCEIRA IDADE E ACESSIBILIDADE - NBR 9050}

\section{Terceira Idade}

Consoante o Estatuto do Idoso (BRASIL, 2013), toda pessoa com 60 anos ou mais é considerada idosa, enquanto que para a Organização Mundial da Saúde (2003) o limite mínimo pode variar: 60 anos ou mais em países em desenvolvimento e 65 anos ou mais em países desenvolvidos.

Apesar do conceito ser tratado de maneira tão simplificada, deve-se reconhecer que o processo de envelhecimento vai muito além de uma classificação cronológica. Isto é, provoca alterações psicológicas e biológicas que variam em função da realidade dos diferentes grupos sociais e econômicos. "Envelhecer é um processo natural que caracteriza uma etapa da vida do homem e dáse por mudanças físicas, psicológicas e sociais que acometem de forma particular cada indivíduo com sobrevida prolongada" (MENDES et al., 2005, p. 2).

"A capacidade funcional pode ser definida como a manutenção da habilidade para realizar atividades básicas da vida diária (ABVD) e atividades instrumentais da vida diária (AIVD), necessárias e suficientes para a manutenção de uma vida independente e autônoma" (FERREIRA et al., 2010, p. 514).

\section{Acessibilidade - NBR 9050}

De acordo com a NBR 9050 (ABNT, 2015), acessibilidade é a "possibilidade e condição de alcance, percepção e entendimento para a utilização com segurança e autonomia de edificações, espaço, mobiliário, equipamento urbano e elementos".

Conceber, portanto, um ambiente acessível, é basicamente proporcionar o fácil acesso ao espaço determinado; entretanto, tal afirmação torna-se relativa, uma vez que, sob as mesmas condições, nem todos os públicos conseguem ingressar no ambiente.

"Para responder com propriedade qual é a acessibilidade de um sistema é necessário compreender: a quem é acessível, em que medida e sob que condições. Só assim será possível afirmar qual é a Acessibilidade Efetiva" (BAPTISTA, 2011, p. 62).

"A Funcionalidade é um termo que engloba todas as funções do corpo, atividades e participação; de maneira similar, incapacidade é um termo que inclui deficiências, limitação da atividade ou restrição na participação" (OMS, 2003).

"Dentre os fatores contextuais está o ambiente construído. Deste modo, quanto maior a adequação do ambiente construído ao usuário, maior será a qualidade de vida das pessoas" (BAPTISTA, 2011, p. 69).

Quando abordada pela OMS (2003), a funcionalidade de um indivíduo num domínio específico é uma interação ou relação complexa entre a condição de saúde e os fatores ambientais e pessoais. Há uma interação dinâmica entre essas entidades: uma intervenção num elemento pode, potencialmente, modificar um ou vários outros elementos. Essas interações são específicas e nem sempre ocorrem numa relação unívoca previsível. 


\section{ESTUDO DE CASO - PROGRAMA CIDADE MADURA JOÃO PESSOA}

O Programa Habitacional Cidade Madura, desenvolvido pela Companhia Estadual de Habitação Popular (CEHAP) do Estado da Paraíba, é o primeiro no Brasil a oferecer um condomínio público exclusivo para idosos e inteiramente projetado para suas necessidades específicas. Em João Pessoa, o Residencial Cidade Madura, inaugurado em junho de 2014, é um condomínio horizontal elaborado pela equipe técnica do setor de Projetos da CEHAP, liderada pelos arquitetos Júlio Gonçalves e Rafaela Mabel Guedes.

A propriedade onde está localizado o condomínio possui área total de 5,07 ha e localiza-se no Conjunto Habitacional Cidade Verde, no bairro de Mangabeira. O local, segundo a CEHAP, foi escolhido por integrar a malha urbana, apresentar acesso fácil, infraestrutura básica, entre outros aspectos. O empreendimento é composto por 40 unidades residenciais com $54 \mathrm{~m}^{2}$ cada, onde podem ser acomodados um ou dois idosos (casal) por habitação e a presença da família é liberada apenas para visitas. Ademais, conta com uma unidade de saúde, praça, horta comunitária, centro de vivência, academia ao ar livre e pista de caminhada (Figura 1).
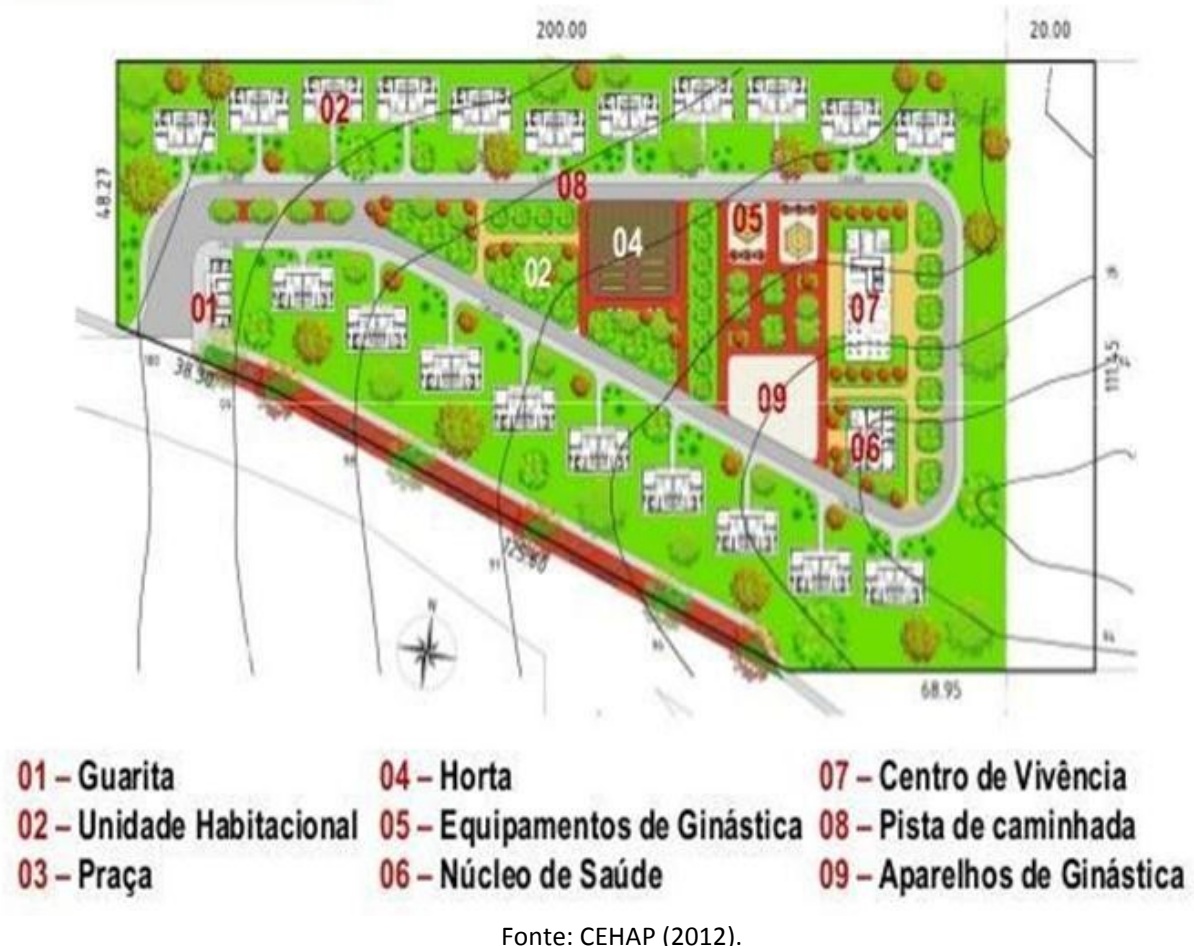

Fonte: CEHAP (2012).

O condomínio ainda apresenta particularidades no que diz respeito ao atendimento do público, pois prioriza os idosos sem oportunidade de qualidade de vida e determina requisitos para participação no programa. Os principais requisitos que o idoso deve possuir, para poder participar do programa são: 
- Possuir 60 anos ou mais e morar sozinho ou com o companheiro(a);

- Receber até 5 salários mínimos e ter condições de se sustentar;

- Possuir autonomia para poder realizar as atividades da vida diária.

Em caso de desistência ou falecimento, o(a) companheiro(a) só poderá permanecer no condomínio se tiver mais de 60 anos.

Quando houver perda de autonomia por parte do idoso, a família é comunicada e o idoso é encaminhado para uma ILPI (Instituição de Longa Permanência para Idosos), por não se encaixar mais nos critérios exigidos para participar do programa, ou se houver outro tipo de descumprimento dos requisitos, a propriedade da casa é devolvida ao Estado e um novo morador é convidado a participar do programa.

\section{METODOLOGIA}

A coleta de dados se deu em dois momentos: no primeiro momento, com relação à pesquisa bibliográfica; no segundo, com relação à pesquisa documental e de campo.

Na pesquisa bibliográfica, os dados foram coletados através de fichas resumos oriundas de teses, dissertações, monografias, artigos e livros que tinham relação com o tema da pesquisa.

Já na pesquisa documental, houve a análise das especificações de serviço e dos projetos arquitetônicos das edificações que compõem o Projeto Cidade Madura, enquanto que na pesquisa de campo, os dados foram coletados por meio de roteiros de observação, os quais foram elaborados a partir dos itens que compõem a NBR 9050 (ABNT, 2015) e registros fotográficos dos itens avaliados, em visitas in loco realizadas pelas pesquisadoras.

A partir da planta baixa das habitações (Figura 2) foi possível coletar os dados complementares para realizar a comparação com a norma técnica de referência (NBR 9050), de modo a verificar a conformidade dos itens. 


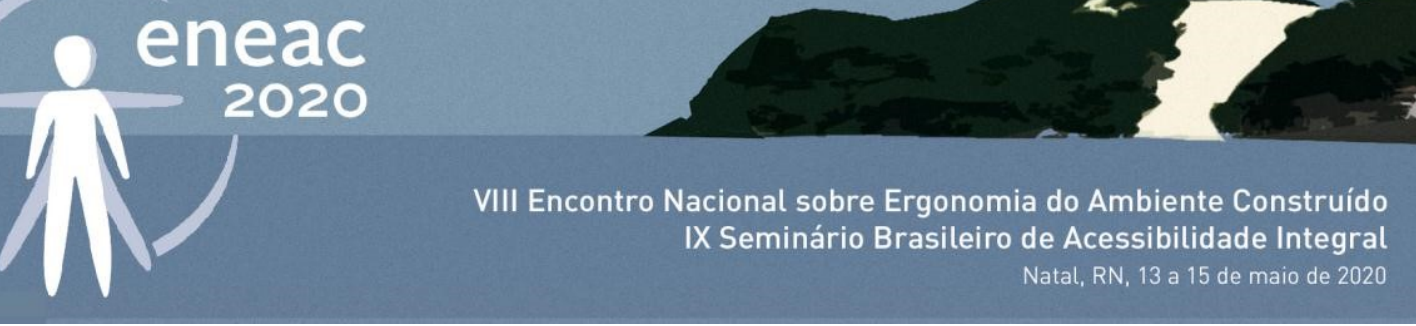

Figura 2: Planta baixa da unidade habitacional

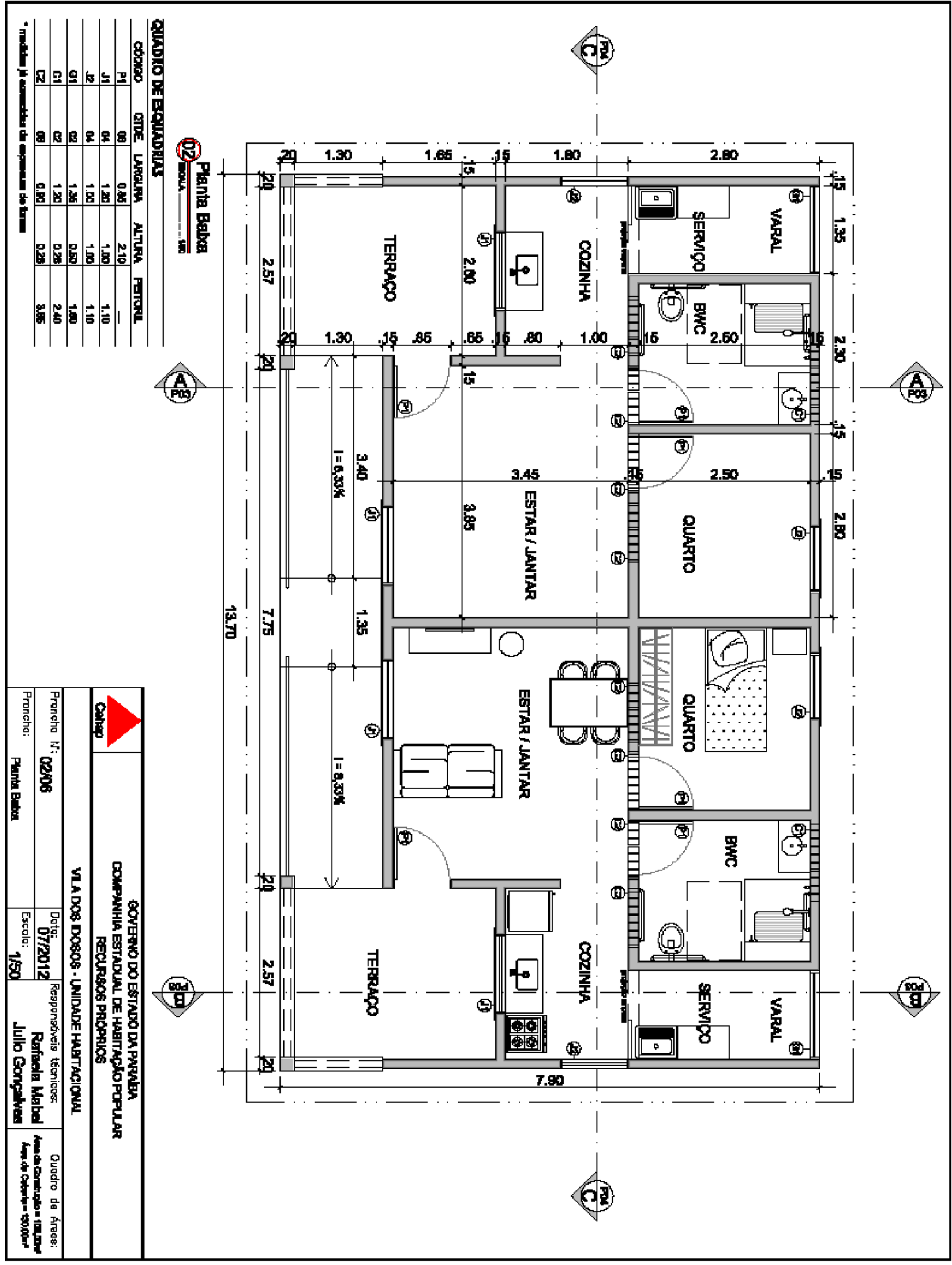

Fonte: CEHAP (2012). 


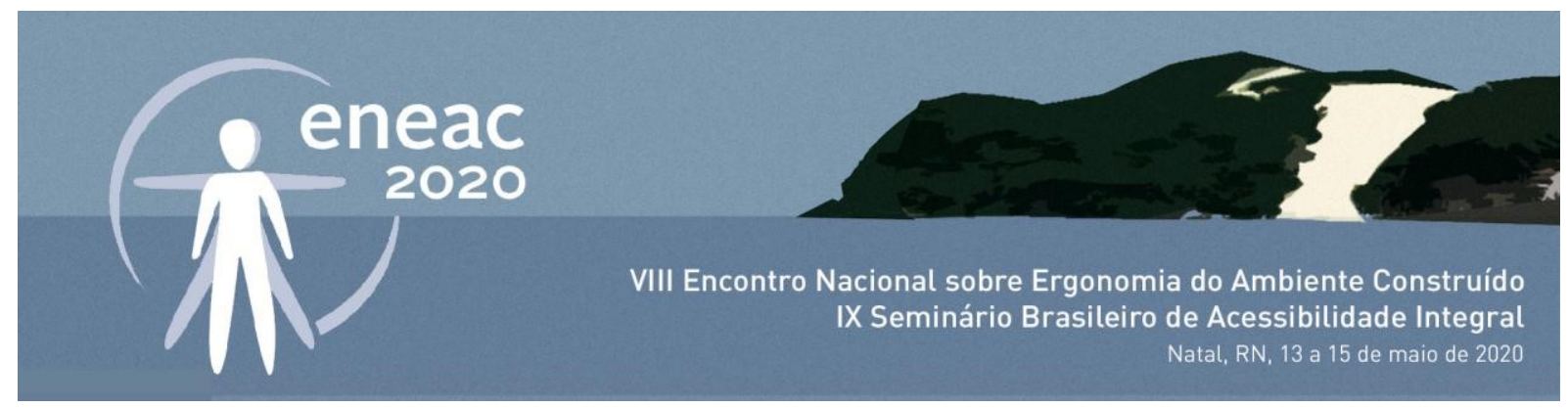

\section{RESULTADOS}

A partir da Figura 2, pode ser observado que as unidades residenciais são distribuídas duas a duas de forma geminada e espelhada. Cada unidade possui seis cômodos: 1 quarto, 1 banheiro, 1 cozinha, 1 sala de estar/jantar, 1 área de serviço e 1 terraço. Dentre os ambientes, somente o banheiro é adaptado para pessoa com deficiência ( $P C D)$, os demais não são adaptados para acesso de cadeira de rodas, pois não possuem dimensões mínimas para a circulação e giro de cadeira de rodas.

A seguir são apresentadas fotos de algumas das edificações que compõem o Programa Cidade Madura, Unidade de João Pessoa (Figuras 3 a 6), e os principais resultados quanto ao atendimento à NBR 9050 (ABNT, 2015).

Figura 3: Unidades residenciais

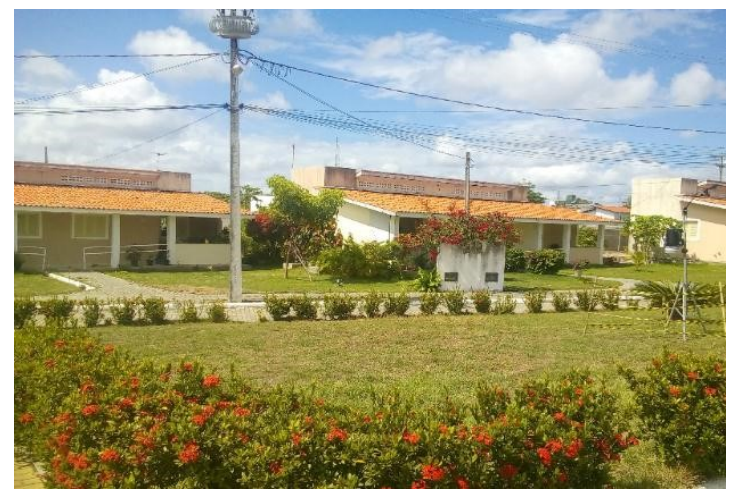

Acervo próprio (2019).

Figura 5: Academia ao ar livre

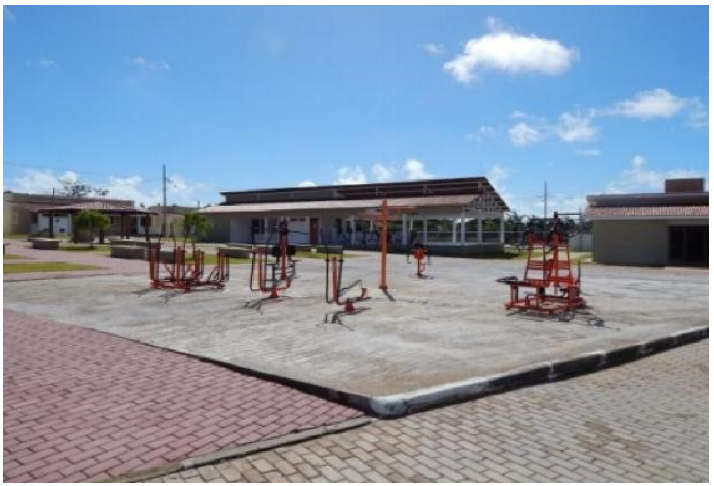

Acervo próprio (2019).
Figura 4: Centro de Vivência

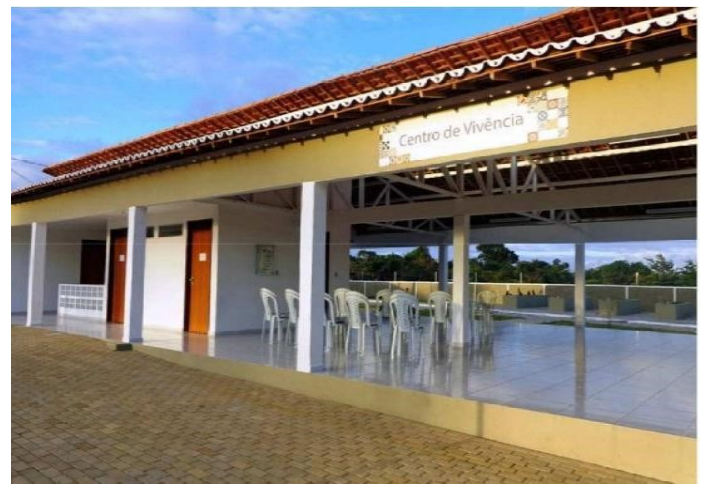

Acervo próprio (2019).

Figura 6: Administração

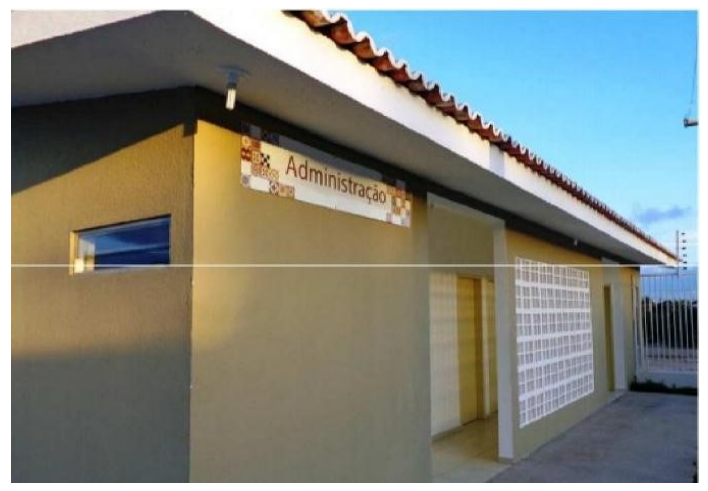

Acervo próprio (2019). 


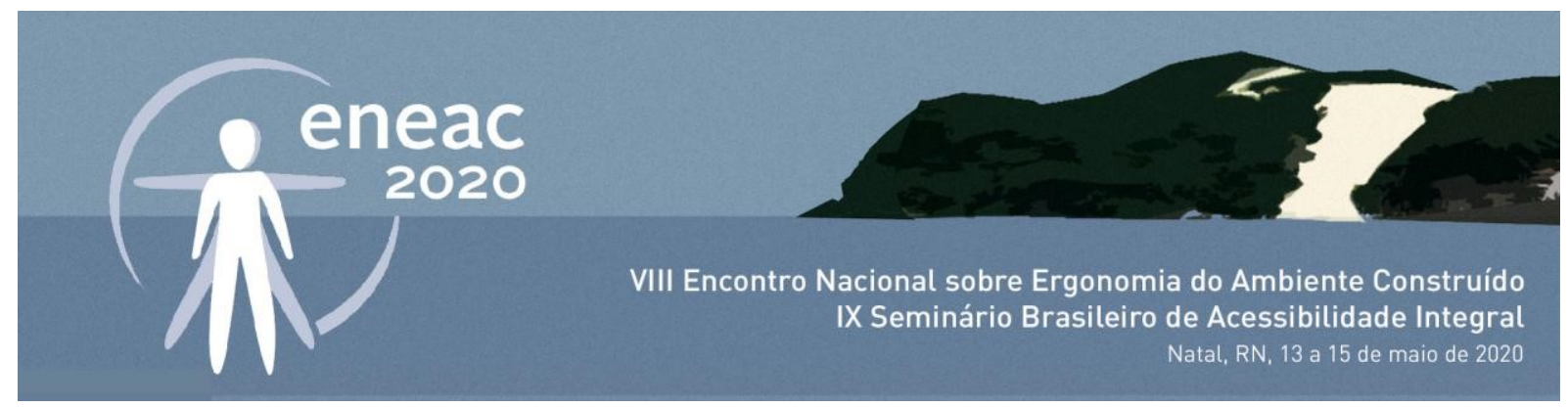

\section{Rampa de Acesso}

O acesso a cada moradia é feito por uma rampa com 3,40 m de comprimento, 1,30 m de largura e inclinação de 8,33\%, adequando-se à NBR 9050 (ABNT, 2015). Entretanto, a largura apresentada encontra-se acima do mínimo admissível de 1,20 m, mas abaixo do valor recomendável de $1,50 \mathrm{~m}$. Ainda assim, levando em consideração que o fluxo cotidiano de pessoas é pequeno, a medida atual não representa uma barreira dentro do ambiente construído.

Apenas um dos lados da rampa possui corrimão, sendo esse de duas alturas, porém não se prologam paralelamente ao piso reto antes do início da rampa, é descontínuo e interrompido por um pilar não indicado em planta. Além disso, não há elementos de segurança, como guarda-corpo - exigido nos casos de falta de parede lateral - e guia de balizamento (Figura 7).

Figura 7: Vista lateral da rampa de entrada

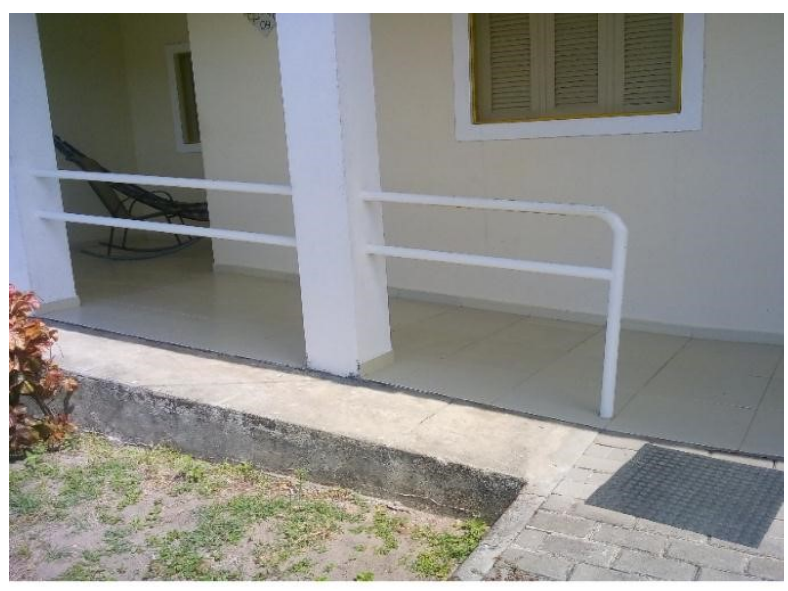

Acervo próprio (2019).

\section{Portas}

Todas as portas das casas (de entrada e internas) possuem $0,85 \mathrm{~m}$ de largura, superando 0 valor mínimo recomendado pela NBR 9050 (ABNT, 2015), que é de 0,80 m. Porém, a abertura de acesso para a área de serviço possui uma largura menor do que o indicado, a qual dificulta a passagem dos moradores que eventualmente precisam transitar pela área com uma pilha de roupas e, consequentemente, gera um ponto de risco à segurança.

Com relação às maçanetas, constatou-se que os seus formatos arredondados dificultam a pegada do idoso e exigem o movimento de torção, ao contrário do modelo alavanca indicado pela NBR 9050 (ABNT, 2015); além disso, na parte de trás da porta do banheiro (Figura 8) não há puxador horizontal para possibilitar o apoio e auxiliar na movimentação da porta. 

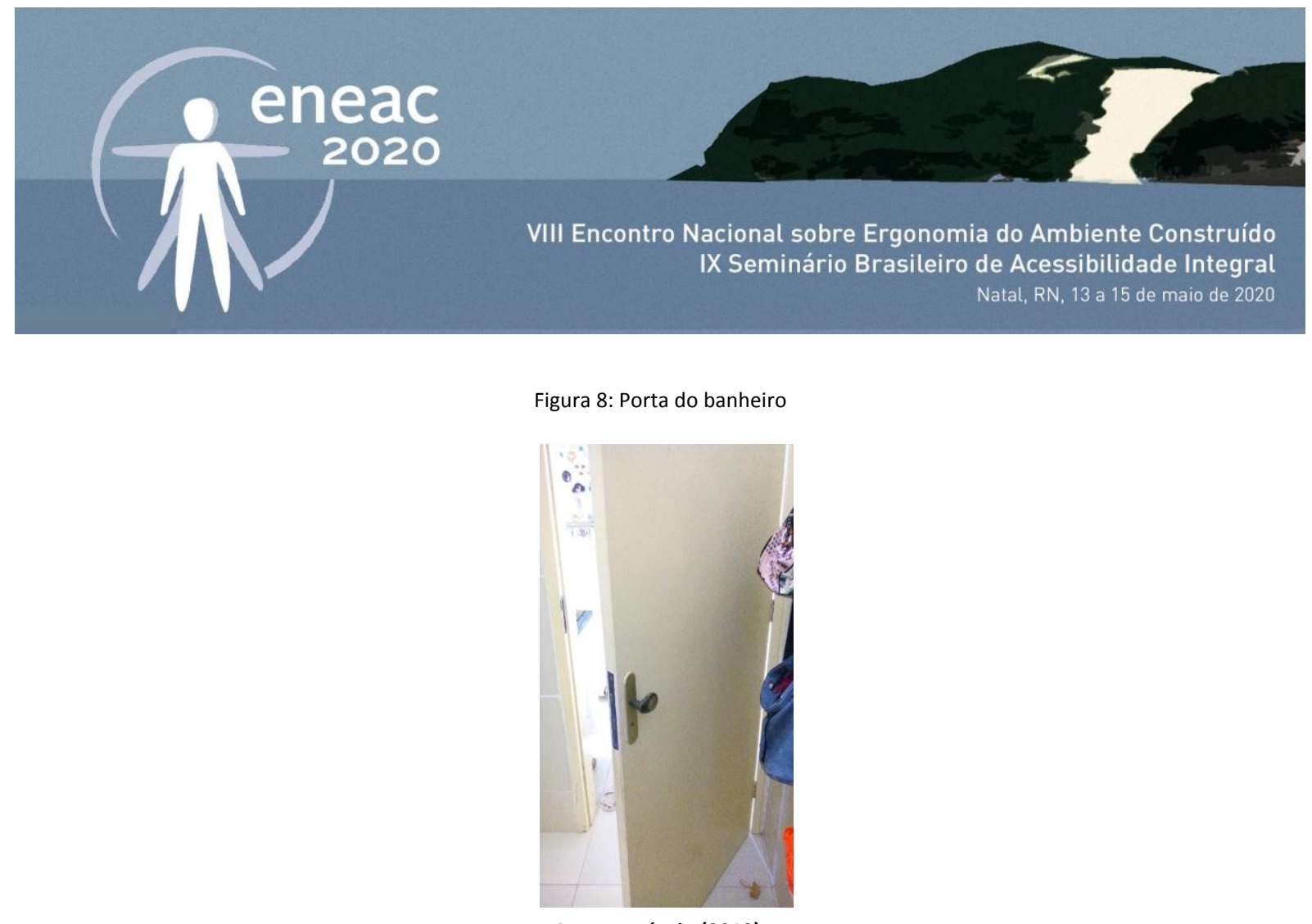

Acervo próprio (2019).

\section{Banheiros}

A porta do banheiro deveria abrir para fora do cômodo, facilitando a prestação de socorro no caso do idoso sofrer algum acidente, como por exemplo uma queda ou desmaio, que impeça a abertura da porta pelo lado de dentro.

No que se refere às barras de apoio necessárias para garantir o uso seguro e autônomo, existem duas barras metálicas horizontais próximas à bacia sanitária, uma na parede de fundo e uma na parede lateral, ambas possuem cerca de $0,80 \mathrm{~m}$ de extensão. Porém, o condomínio descumpre a NBR 9050 (ABNT, 2015) devido à falta não só da barra vertical que deveria ser fixada na parede lateral um pouco acima do apoio horizontal existente, como das barras que ficariam nas laterais do lavatório, podendo ser horizontais e/ou verticais.

Já dentro do boxe, pode-se afirmar que foram atendidas as medidas mínimas de comprimento e largura definidas por norma $(0,90 \mathrm{~m} \times 0,95 \mathrm{~m})$. Do mesmo modo, foi seguida a exigência de um banco com cantos arredondados, superfície antiderrapante impermeável e profundidade e comprimento satisfatórios (Figura 9). Cabe destacar que todas as barras indicadas na norma são encontradas: uma barra vertical na parede onde está fixado o banco, uma horizontal e uma vertical na parede que contém a torneira e o chuveiro. 


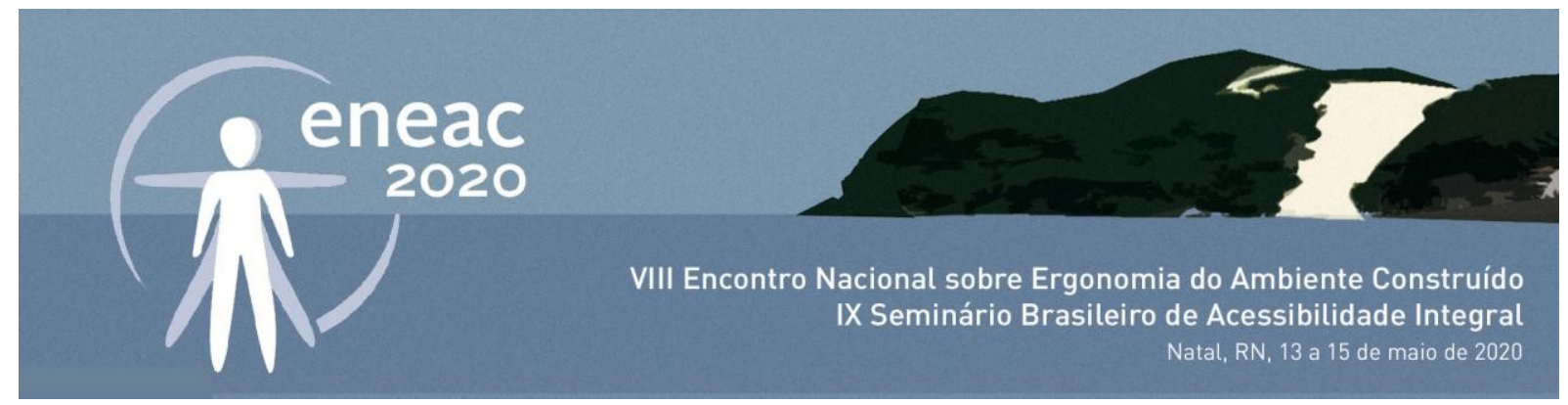

Figura 9: Banco articulado dentro do box

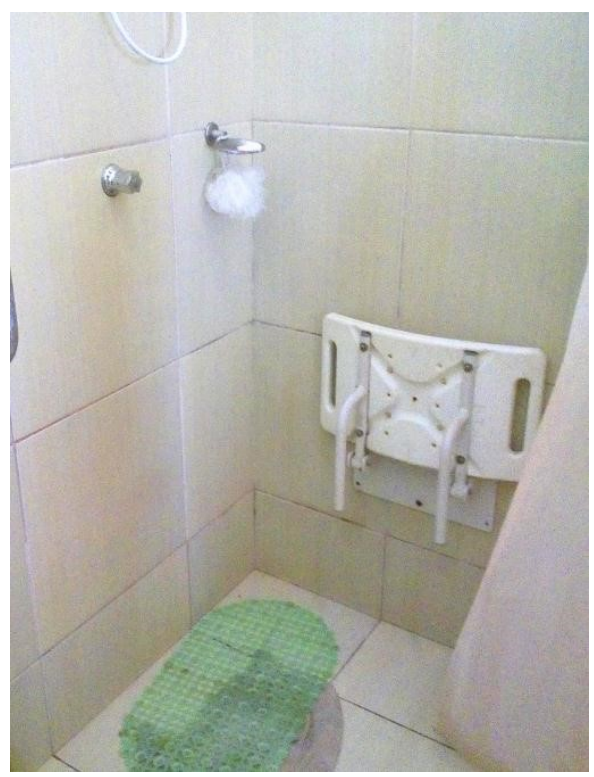

Acervo próprio (2019).

\section{CONSIDERAÇÕES FINAIS}

Dos itens abordados neste artigo, relativos à adequação das habitações do Programa Cidade Madura (Unidade de João Pessoa) à NBR 9050 (ABNT, 2015), constatou-se que nenhum deles atende, em sua totalidade, às disposições preconizadas na referida norma. Todos, sem exceção, atendem de forma parcial às disposições, sendo as situações mais críticas encontradas nas rampas de acesso às habitações, nas portas e nos banheiros.

Entretanto, também pôde ser constatado, através de visitas in loco, que o condomínio se constitui em um espaço em que os moradores são protegidos, integrados e incentivados a permanecerem ativos e a derrubar a visão preconceituosa que os classifica como incapazes.

Por fim, ressalta-se que mesmo com as inadequações encontradas, com relação às disposições contidas na NBR 9050 (ABNT, 2015), o programa é um avanço no que diz respeito a moradias específicas para a terceira idade. Todavia, também deve ser ressaltada a importância da necessidade de ajustes no programa, de forma a atender, em sua totalidade, às disposições da NBR 9050 (ABNT, 2015) e ser replicado para as demais unidades do programa que ainda não foram construídas, em cidades paraibanas.

\section{AGRADECIMENTOS}

As autoras agradecem à CEHAP, pela viabilização da pesquisa através do fornecimento de dados, e ao IFPB - Campus João Pessoa, pela bolsa concedida e ajuda de custos. 


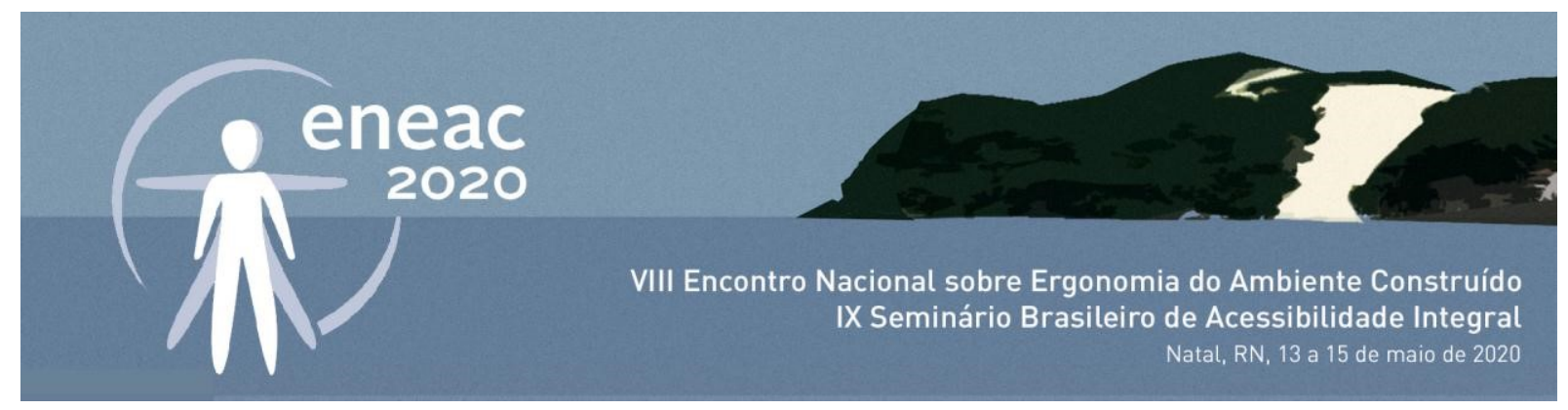

\section{REFERÊNCIAS}

ASSOCIAÇÃO BRASILEIRA DE NORMAS TÉCNICAS. NBR 9050 - Acessibilidade a edificações, mobiliário e equipamentos urbanos. Rio de Janeiro, 2015.

BAPTISTA, A. H. N. Critérios para uma teoria de acessibilidade efetiva. In: MONT’ALVÃO, C.; VILLAROUCO, V. (org.). Um novo olhar para o projeto: a ergonomia no ambiente construído. Teresópolis: 2AB, 2011.

BRASIL. Ministério da Saúde. Estatuto do Idoso. 3. ed., 2. reimpr. Brasília: Ministério da Saúde, 2013.

COMPANHIA ESTADUAL DE HABITAÇÃO POPULAR. Projeto Cidade Madura. João Pessoa: CEHAP, 2012.

FERREIRA, O. G. L. et al. O envelhecimento ativo sob o olhar de idosos funcionalmente independentes. Revista da Escola de Enfermagem da USP, São Paulo, v. 44, n. 4, p. 1065-1069, 2010.

MENDES, M. R. S. S. B. et al. A situação social do idoso no Brasil: uma breve consideração. Acta Paulista de Enfermagem, São Paulo, n. 18, v. 4, p. 422-426, 2005.

ORGANIZAÇÃO MUNDIAL DA SAÚDE. CIF: Classificação Internacional de Funcionalidade, Incapacidade e Saúde. São Paulo: Universidade de São Paulo, 2003.

QUEIROZ, G. A. Qualidade de vida em instituições de longa permanência para Idosos: considerações a partir de um modelo alternativo de assistência. 2010. 140 f. Dissertação (Mestrado em Psicologia) - Departamento de Psicologia, Universidade Federal de São João Del Rei, São João Del Rei, 2010.

VINAGRE, A. P. Residência para a terceira idade. Revista Especialize On line IPOG. Goiânia, 12. ed., v. 01, dez. 2016. Disponível em: <https://www.ipog.edu.br/revista-especialize-online/edicao-n12-2016/residencia-para-aterceiraidade/>. Acesso em: 25 jan. 2019. 